\title{
Current Challenges of the Technology Transfer Process
}

\author{
Josef TOMAN and Blanka KLÍMOVÁ* \\ University of Hradec Králové, Hradec Králové, Czech Republic; josef.toman@uhk.cz, blanka.klimova@uhk.cz \\ * Correspondence: blanka.klimova@uhk.cz
}

\begin{abstract}
Currently, science and technology transfer are considered to be the cornerstones of economic and social progress. The importance of technology transfer is of strategic importance for each state. Therefore, the purpose of this review article is to examine the current issues challenging the process of TT from the perspective of knowledge management. On the basis of the literature review, the authors identified the persisting three issues, significantly affecting the TT process: (i) the ability of a university to identify a target company for a given technology, (ii) the ability of scientists to identify and subsequently locate technologies that someone is interested in, and (iii) slowness and inflexibility of universities in formulating agreements. These issues are discussed in detail in this article.
\end{abstract}

Keywords: technology transfer; knowledge management; non-linear model of TT process

JEL Classification: O31; O32; O33

\section{Introduction}

Science and its technologically usable output in developed countries are generally accepted as the main pillars of economic and social progress (Wahab et al. 2011). Especially universities play a unique role in this technology transfer (TT) process as they are able to provide a community of experts with a potential for innovation. The TT from the university to the commercial environment is classified as vertical, while the TT between two commercial entities is classified as horizontal. The vertical transfer, i.e. TT between a university and a commercial firm, is usually defined for the segment of mediumsized companies, i.e. companies with more than 50 and less than 250 employees.

It turns out that one of the preconditions for a successful TT is the existence of an experienced and well-established technology transfer office (TTO) team, which is connected with the question of TT productivity. Productivity is measured using the Maturity Model (Secundo et al. 2016). Alternatively, one can use the European Innovation Scoreboard, which works with 25 indicators, ranging from the number of doctoral graduates, scientific publications, patents, trademarks to research costs, providing innovation indices for each country (Hollanders et al. 2019) - (consult Figure 1. ). In Figure 1, the individual countries are plotted on the horizontal axis and the corresponding innovation indexes are subtracted on the vertical axis. Figure 1 contains two data series of innovation indexes; one, a gray weak bar for 2011 and the other, a stronger color bar, for 2019. For a better orientation, groups of countries are color-coded with regard to their level of innovation, i.e. modest innovator, moderate innovator, strong innovator and innovation leader. The innovation leaders traditionally include Scandinavian countries, followed by Benelux countries.

TT is generally considered to be an extremely important process, improving local economic development, and therefore all the difficulties that have an impact on the productivity of this process are thoroughly examined. The main difficulties of TT in developed countries are the following: (i) the ability of the university to identify the target company for the technology, (ii) the ability of scientists to identify and subsequently locate technologies of interest. Close to these problems is (iii) the slowness and inflexibility of universities in formulating agreements (Decter and Bennett 2003).

The purpose of this article is to examine the current issues challenging the process of TT from the perspective of knowledge management. 


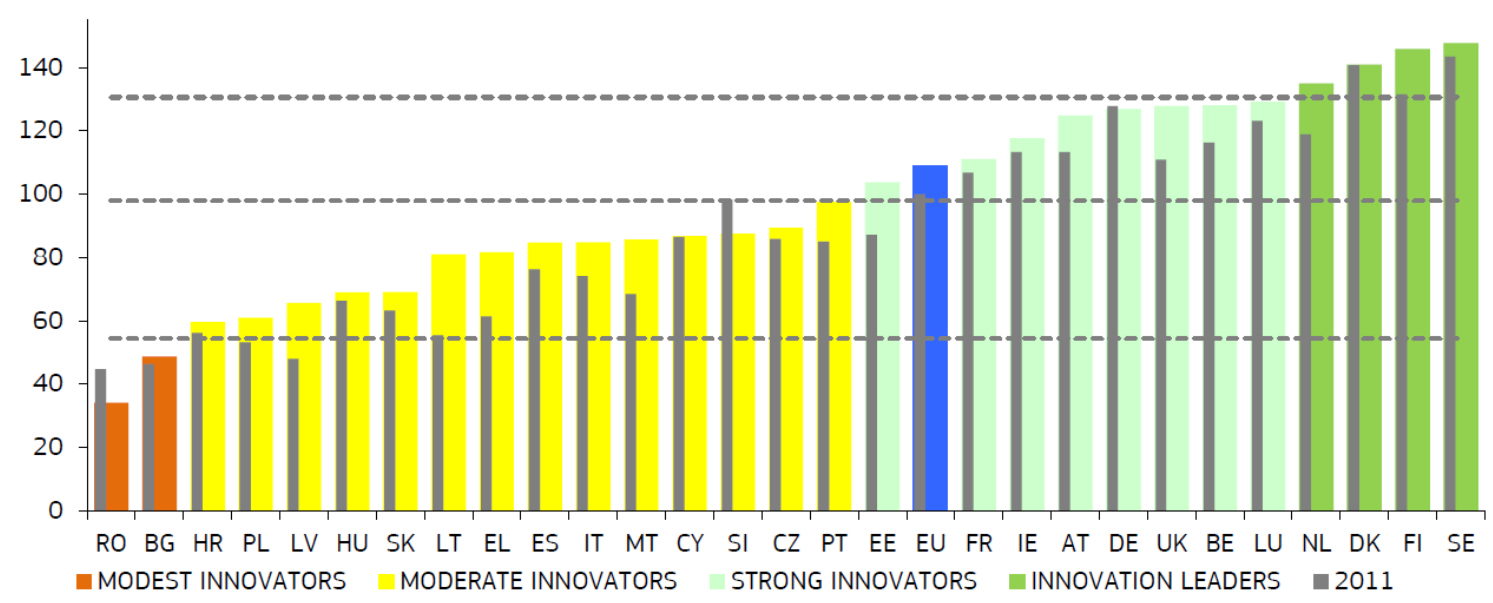

Figure 1. European Innovation Scoreboard: source (Hollanders et al. 2019).

\section{Methodology}

The literature review was chosen to explore current knowledge, obtain and organize dispersed findings to ensure a shared understanding of the subject under investigation.

Only the peer review research articles written in English were detected from scientific databases: Scopus and Web of Science. The time interval for searching in the above mentioned databases was chosen to cover the last five years (from January 2015 to December 2019) of the development of knowledge on the basis of the research topic, i.e. current challenges in the technology transfer process. The articles has to contain definitions of the terms, as well as to provide the information explaining how individual variables were measured. A total of 106 academic articles were obtained. After screening for abstracts and article titles, 63 articles were discarded. After a detailed evaluation, another 32 articles were excluded due to duplications, insufficient data, unclear research intent and language. Alternatively, no link was found to the research question of this study. Finally, 11 research articles were included into this study (Figure 2).

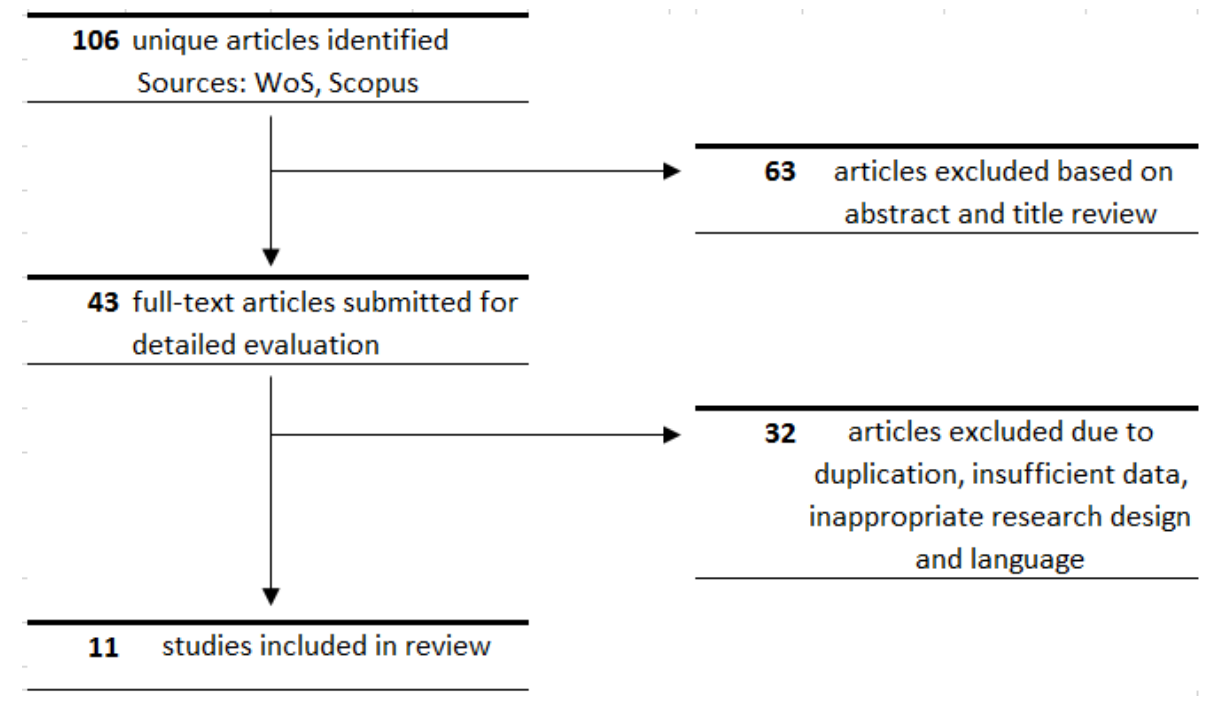

Figure 2. The selection procedure.

\section{Results}

The results are based on a review of 11 scientific articles exploring the relationship between KM and TT. These findings indicate that the difficulties described in the part of Introduction still persist in new roles related to the re-evaluation of the traditional role of universities as producers and knowledge disseminators (Fayolle and Redford 2015). Thus, the authors identified the following three 
new changes significantly affecting the TT process: (i) the ability of a university to identify a target company for a given technology, (ii) the ability of scientists to identify and subsequently locate technologies that someone is interested in, and (iii) slowness and inflexibility of universities in formulating agreements.

\subsection{The ability of a university to identify a target company for a given technology}

The university's ability to identify a target society for a given technology has been explored by many authors in the doctrine of the dependence of the economies of developed countries on knowledge (Iwasaki and Tokunaga 2016), (Siegel et al. 2004). Today's research does not focus on whether or not the TTO should actively participate in commercialization ( $\mathrm{O}^{\prime}$ Kane et al. 2015). The key factor seems to be whether we understand the conditions (Omobhude and Chen 2019) in which identification roles need to be fulfilled during the TT process (Roldán Bravo et al. 2019). And the question of the added value of a TTO today is rather in the position of whether or not the existence of a TTO can explain (i) the lack of patent management experience of universities and (ii) the lower value of patents owned by the university compared to the value of patents owned by a commercial entity (Sterzi et al. 2019).

The starting point seems to be to abandon the linear model of TT (Siegel et al. 2004), according to which the recipient of the technology (patent) enters the process at its very end. The replacement with the non-linear TT process (Hall and Rosenberg 2011) is self-evident and makes it possible to investigate the phenomena of proximities (Omobhude and Chen 2019) in the necessary interaction cycles that allow the actors of the TT process to receive and share knowledge (Roldán Bravo et al. 2019). It is beneficial to take time and step aside, i.e. towards the horizontal TT area, where problems addressed here and somewhat remote to the academic community are commonplace in the commercial area (Fredriksson et al. 2019).

\subsection{The ability of scientists to identify and subsequently locate technologies that someone is interested in}

The key study originated in Singapore (Cheah et al. 2019). The authors of this study conducted a survey among the 30 leading industry leaders in Singapore. The aim of the study was to identify technologies that will enable the manufacturing industry to build new capabilities primarily in areas related to (i) advanced competence and intelligence of customers, (ii) socio-physical quality of service and (iii) integrated strategic decision making (Cheah et al. 2019). The reciprocal iterations of the provider and recipient of the technology, due to their geographical, cognitive, organizational, social or institutional proximity, allow for the effective sharing of both tacit and explicit knowledge (Omobhude and Chen, 2019). This iterative process allows the recipient to identify the technology needed more efficiently than in the linear TT process (Siegel et al. 2004), even in a dynamically changing socioeconomic environment (Jiang et al. 2018). The ability of scientists to identify and subsequently locate technologies according to the needs of the recipients is therefore of considerable scientific interest and the level of understanding of the issue is significant. Nevertheless, it is advisable to be inspired by the commercial world of horizontal TT, which seems to provide a deeper insight into the issue of identifying and subsequently locating the technology with the recipient by its provider (Fredriksson et al. 2019).

\subsection{Slowness and inflexibility of universities in formulating agreements}

The slowness and inflexibility of the university may be related, on the one hand, to the considerable diversity of projects carried out (Sandberg et al. 2015), and on the other, to the unclear identity of the TTO (O'Kane et al. 2015) and the commercial inexperience of academics (O'Kane et al. 2015).

\section{Discussion and Conclusion}

Firstly, the question of the ability of a university to identify the target company for a given technology needs to be discussed. We have mentioned that the starting point could be to leave the 
linear model, which captures the process of technology transfer, including the phase of commercialization of research. It defines the various steps of the phases as follows: scientific discovery; disclosing the invention; evaluating the invention for patenting; patent; technology marketing for companies; arranging a license; and company license (Siegel et al. 2004). The ability to identify the target recipient is indicated by the activity in the process - technology marketing for companies - but it is not clear who will perform the activity. Traditionally, this has been the task of TTO, which involves not only the transfer of technology but also the commercialization of research, which is the process of turning inventions into marketable products (Secundo et al. 2016). Given the identified dual identity of TTOs (O'Kane et al. 2015) and the associated limited commercial capability (Sterzi et al. 2019) discussed below in relation to the slowness and inflexibility of TTOs in concluding agreements, TTo seems not to be an appropriate actor to perform this important activity. Why should it be a departure from a linear process? We argue that, on the basis of our findings, it seems obvious that the European non-linear concept (Hall and Rosenberg 2011) allows the technology provider and the technology acquirer to interact in repeated iterative cycles that begin before the agreement on the implementation of the research (patented academic invention). This interaction is not formal, but it is a creative interaction of the research teams from both the university and the technology recipient (Hall and Rosenberg 2011). Moreover, such a recurring cyclic interaction of various team members between the university and industry makes it possible to exploit different levels of proximity (geographic, cognitive, or social), which has a proven significant impact on the sustainable development of technology (Omobhude and Chen 2019).

Secondly, there is a question of the ability of scientists to identify and locate the technologies that someone is interested in. According to the linear model, the ultimate invention, i.e. the product, is largely conceived, created and fine-tuned by a team of inventors with a minimal possibility to influence this process from the position of the recipient. Our findings present an environment and conditions for identifying and subsequently locating the technology for a specific recipient that is directly opposite to the linear TT model. We argue that it is not only possible to identify suitable technologies for the recipient, but it is possible to identify these technologies in the context of the necessary capabilities that the recipient of the technology must have to stand up to its competitive environment (Cheah et al. 2019). In addition, based on the findings, we argue that, from the perspective of sustainable technology development, it is essential to shape and maintain a creative environment (Omobhude and Chen 2019) that will allow repeatable technology transfers. The reciprocal iterations of the provider and the recipient of the technology due to their geographical, cognitive, organizational, social or institutional proximity make it possible to create space for the effective sharing of both silent and explicit knowledge (Nonaka et al. 2000).

Finally, the issue of slowness and inflexibility of universities in formulating agreements should be discussed. There are contradictory views on the role of TTOs, which can be defined by extreme positions: (i) TTOs are of strategic importance to universities, especially in the field of commercialization, and (ii) the existence or absence of TTOs on the patenting activities of the university does not change anything. We are forced to take the second extreme view, i.e. the existence or absence of TTOs on the patenting activities of the university does not change anything because based on our findings we can argue that: (i) with regard to the unclear identity of TTOs (O'Kane et al. 2015), there is some "hesitation" on the part of scientists to cooperate with TTOs, leading to a loss of readiness or "slowness" in dealing with potential firms and (ii) The existence or absence of a Technology Transfer Office (TTO) at the time of the patent application does not change the following: (1) universities own inventions of lower technological significance and gain a smaller value from the related patents and (2)universities show a relative lack of experience in patent management.

Acknowledgments: This paper is supported by SPEV project 2020, run at the Faculty of Informatics and Management of the University of Hradec Kralove. 


\section{References}

Cheah L. Sarah, Yang Yinping, and Saritas Ozcan. 2019. Reinventing product-service systems: The case of Singapore. Foresight: 21(3), 332-361. https://doi.org/10.1108/FS-12-2018-0107

Decter Moira, and Bennett David. 2003. Factors influencing the success of university to business technology transfer-A UK and USA comparative study. Paper presented at the 12th International Conference on Management of Technology, Nancy, France, May 13-15. https://doi.org/10.13140/rg.2.1.1353.3921

Hall H. Bronwyn, and Rosenberg Nathan. 2011. Handbook of the economics of innovation. North Holland.

Hollanders Hugo, Es-Sadki Nordine, and Merkelbach Iris. 2019. European Innovation Scoreboard 2019. Available online: https://ec.europa.eu/docsroom/documents/38781/attachments/1/translations/en/renditions/native (accessed on 30 January 2020).

Iwasaki Ichiro, and Tokunaga Masahiro. 2016. Technology transfer and spillovers from FDI in transition economies: A meta-analysis. Journal of Comparative Economics: 44(4), 1086-1114. https://doi.org/10.1016/j.jce.2016.10.005

Jiang Wenbo, Chai Huaqi, Shao Jing, and Feng Taiwen. 2018. Green entrepreneurial orientation for enhancing firm performance: A dynamic capability perspective. Journal of Cleaner Production: 198, 1311-1323 https://doi.org/10.1016/j.jclepro.2018.07.104

Nonaka Ikujiro, Toyama Ryoko, and Konno Noboru. 2000. SECI, Ba and Leadership: A Unified Model of Dynamic Knowledge Creation. Long Range Planning: 33(1), 5-34. https://doi.org/10.1016/S0024-6301(99)00115-6

O'Kane Conor, Mangematin Vincent., Geoghegan Will, and Fitzgerald Ciara. 2015. University technology transfer offices: The search for identity to build legitimacy. Research Policy: 44(2), 421-437. https://doi.org/10.1016/j.respol.2014.08.003

Omobhude Christian, and Chen Shih-Hsin. 2019. The Roles and Measurements of Proximity in Sustained Technology Development: A Literature Review. Sustainability: 11(1), 224. https://doi.org/10.3390/su11010224

Roldán M. Bravo, Stevenson Mark, Moreno A. Ruiz, and Lloréns F. J. Montes. 2019. Absorptive and desorptive capacity configurations in supply chains: An inverted U-shaped relationship. International Journal of Production Research: 1-18. https://doi.org/10.1080/00207543.2019.1642530

Secundo Giustina, De Beer Christle, and Passiante Giuseppina. 2016. Measuring university technology transfer efficiency: A maturity level approach. Measuring Business Excellence: 20(3), 42-54. https://doi.org/10.1108/MBE-03-2016-0018

Siegel S. Donald, Waldman A. David, Atwater E. Leanne, and Link N. Albert. 2004. Toward a model of the effective transfer of scientific knowledge from academicians to practitioners: Qualitative evidence from the commercialization of university technologies. Journal of Engineering and Technology Management: 21(1-2), 115142. https://doi.org/10.1016/j.jengtecman.2003.12.006

Sterzi Valerio, Pezzoni Michele, and Lissoni Francesco. 2019. Patent management by universities: Evidence from Italian academic inventions. Industrial and Corporate Change: 28(2), 309-330. https://doi.org/10.1093/icc/dty070

Wahab A. Sazali, Rose Ch. Raduan, and Osman L. W. Suzana. 2011. Defining the Concepts of Technology and Technology Transfer: A Literature Analysis. International Business Research: 5(1). https://doi.org/10.5539/ibr.v5n1p6 